\title{
INFLUENCE OF ENGLISH AS A SECOND LANGUAGE ON THE TRAINEES' ACADEMIC PERFORMANCE AT EENHANA VOCATIONAL TRAINING CENTRE IN NAMIBIA
}

\author{
Hambeleleni Albertina Nepolo ${ }^{1}$ and Ifeoma R. Eze ${ }^{2}$ \\ ${ }^{1}$ Department of Education and Language Skills, Botho University, Botswana \\ ${ }^{2} \mathrm{PhD}$, Department of Educational Management and Leadership, Botswana Open University, Botswana
}

\begin{abstract}
It has been observed that the low academic performance of trainees at the Windhoek Vocational Training Centre has been on the increase at an alarming rate without any proven reasons Malwa (2018). This may be the case in other vocational training centres. Thus, this study examined the influence of English as a Second Language on trainees' academic performance at Eenhana Vocational Training Centre in Namibia. The study, therefore, tried to answer these questions; (a) What factors in English influence trainees' academic performance? (b) How did the influence of English as a Second Language and medium of instruction affect other subjects? (c) How did the trainees comprehend their academic work? '.This is a qualitative study which used the snowball sampling method to select 5 trainers and 10 trainees as participants.'. The data were collected through face-to-face interviews, participants observations and documentexaminations. Narrative and thematic analysis were used in analyzing data. The study revealed that the performance of trainees in their academic work is determined by their ability to understand English as a Second Language. Their proficiency level in English influences how best or poorly they can perform in their academic work.,. It was also found that trainees who have poor English language proficiency find it difficult to understand their subjects content and also performing their best in academic work, while those who are good at the language perform well academically as they can understand what they are learning and they can handle the assessment activities appropriately. The study will inform the Higher Education policymakers, trainers, and trainees as it enhances an understanding of the influences of English as a medium of instruction on other subjects for them to employ the best teaching and learning strategies such as Access or bridging courses to improve the problem caused by the language barrier.
\end{abstract}

\section{KEYWORDS}

Eenhana Vocational Training Centre, English as Second Language, Trainees' Academic Performance

\section{INTRODUCTION}

Namibia is a multilingual country of at least 14 languages due to different ethnic groups such as Herero, Damara, Nama, Kwanyama, Ndonga and so forth, but with only one language as the official language and medium of instruction across the curriculum. This language got into use when the South West Africa People's Organisation (SWAPO) language policy decided English to be an official language and the only language of communication throughout all government sectors (Frydman, 2011).

English as a Second Language being an important and official language in the country, prompted the curriculum designers and education's national assessment and evaluation to set up the language promotional and admission requirements from primary level grades, Grade 1 to secondary level Grade 12, as well as to higher institutions of education. This implies that to pass grade 10, a pass with 23 points and Grade 12 , a pass with 25 points with or at least $\mathrm{E}$ or better in English as a minimum entry requirement to tertiary education levels should be achieved, as it is said that a learner in Grade 10 or 12 should be promoted to another level if he or she has obtained an $\mathrm{E}$ grade or better in 5 five subjects out of six subjects including English (Hanse- Himarwa 2017). Some of the tertiary institutions where learners go to further their studies are vocational training centres, which train and prepare trainees with knowledge and skills to be used in technical aspects of the job market. 
The vocational training centres admit those who have just ended up at or completed Grade 10 and do not meet the entry requirements for Grade 11 to 12 . They also admit those who have completed Grade 12 and do not meet the admission requirements for universities and other institutions which focus on academic comprehension. In addition, the Namibian education policy has a provision of training the marginalized and vulnerable ethnic groups such as; the San and the Himba, despite not having schooled up to grade 10 or 12 , which are the entry grades into vocational training centres.

Despite the school phases or grade levels achieved, for instance, Grade 10 or 12, when training or teaching is being done, it is always delivered in English language as the medium of instruction. All the trainees with different grade levels achieved, which are either Grade 10 or 12, or the marginalized and vulnerable ones who may not have done any of the two grade levels are all taught in the same classrooms, receiving the same subject content, and do the same assessments in English as a medium of instruction. As a prerequisite for graduation, these trainees are expected to pass all the modules they are doing in their trades, and get into the job market in which they can interact with speakers of different languages.

In India, it is also an inherited language and is used as a second language and a medium of instruction in most of the schools, and it is claimed that learners struggle to master the language skills which are listening, reading, speaking and writing. This results into the language anxiety among students, as it negatively affects the students' academic performance (Ujjwal 2018). Literature also revealed that foreign languages which are used as second languages in schools do not become effective predictor of the primary education's academic performance, but at the upper education levels like secondary and tertiary levels. It is regarded as the main contributor to the academic failure and importantly academic achievement (Tuncer \& Dogan 2015).

\section{THEORETICAL FOUNDATIONS}

This study is focused on the influences of English as a Second language in academic performance. Nath (2010) defines language as a way in which thoughts are well arranged in a manner that meanings can be formed and understood. To provide an understanding of this practice, language and academic performance were studied by Vygotsky, as a theorist, and it was indicated that there is a correlation between the two. It was shown that academic performance depends on the ability to use the language of instruction. He explained this as a Zone of Proximal Development (ZPD). It explains that the gap between what the children can comprehend by themselves and what can be understood with assistance, indicating that a leaner needs to be supported quickly up a learning curve, and their ZPD can continuously be advanced with necessary help (Fry Ketteridge \& Marshall, 2009). This idea is very much into scaffolding learning, which entails that for someone to learn something, help, and support should be provided. This is illustrated in the diagram below:

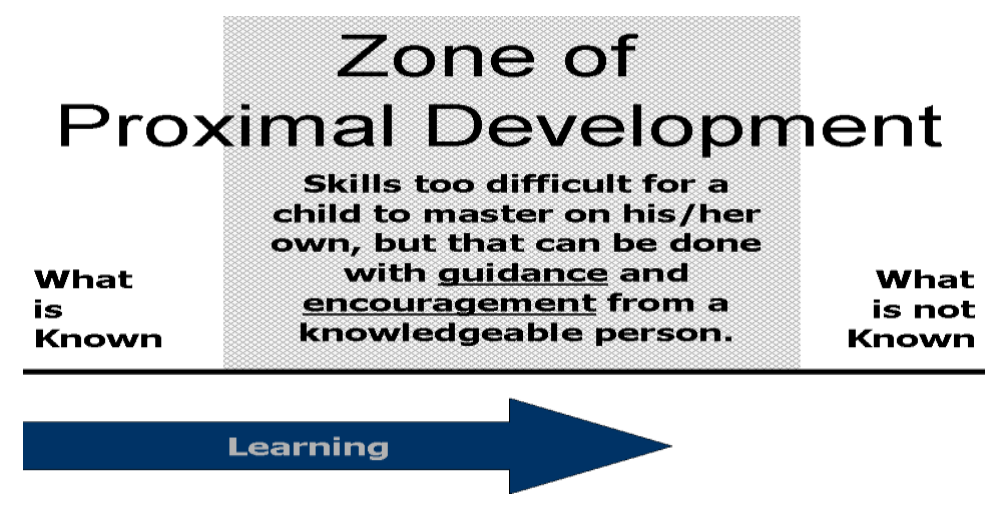

Figure 1. Source: McLeod (2019) The Zone of Proximal Development and Scaffolding https://www.simplypsychology.org/Zone-of-Proximal-Development.html

Vygotsky claims that the cognitive development of students is driven by the use of language, as the student can only be able to learn how to think and internalize the complex concepts which may enhance understanding of the learned aspect (Dahms, Geonnotti, Passalacqua, Wetzel, Schilk \& Zulkowsky, 2007). This implies that learning happens via the use of language, which enables the transformation of perceived experience into the internal processes. This promotes learning, which may enhance performance as what is being learned can be 
understood (Mlay 2010). Vygotsky further indicated that a language first acts as a social communication which enhances proper understanding of concepts, which leads to mental development that may promote learning.

It is further stated that the capacity to use mental functions at higher levels, such as in thinking, reasoning, and logical processing of memory are led by the usage of language (Culligan 2013). That means correct thinking and learning, which may enhance academic performance, mainly occurs if there is an understanding of the concepts being learned. Vygotsky also asserts that as language is used for communication, then it can be used in playing a significant role in the mental development of students, which may also indirectly transform what is perceived during communication into meaningful understanding (Culligan 2013). Vygotsky then suggests that students' understanding of what they are learning may become their mental resources, which they may later use in their academic activities (Culligan 2013).

\section{STATEMENT OF THE PROBLEM}

Most of the trainees at the vocational training centres are those who obtained low points in their previous grades which are grade 10 and 12 , the points which may not qualify them to be able to do courses which require cognitive usage but rather technical subjects, which just require (hands-on) skills. They at least obtained an $\mathrm{E}$ or better in English as a Second Language. Obtaining an E or better in English is considered as one of the least grades a candidate can obtain in examination. The candidates who obtained such an E grade did not reach the good passing mark, which is 50. It indicates that some language learning aspects were required to be learned for better performance, either in English or other subjects, to be achieved.

Some trainees had never been in grade 10 or 12 . These are the marginalized people who get admitted due to the Ministry of Education's provision that the marginalized and vulnerable tribe groups should be admitted to institutions of higher learning. Based on the types of trainees at vocational training centres, this study tried to examine the influences of English as a Second Language on trainees' academic performance at Eenhana Vocational Training Centre. This is because proficiency of English as a Second Language is the most influencing factor on the academic performance of trainees (Sadeghi, Kashanian, Maleki. \& Haghdoost, 2013).

\section{PURPOSE OF THE STUDY}

Enter the text here. The study examined the influences of English as Second Language on the trainees' academic performances at Eenhana Vocational Training Centre in Ohangwena Region, Namibia. The investigation was guided by the following objectives, which were to:

- examine how English as a Second Language influences the academic performance of trainees

- identify how the influence of English as a Second Language and medium of instruction affects other subjects

- examine how trainees comprehend their academic work

\section{SIGNIFICANCE OF THE STUDY}

Finding out how English as a Second Language influences the trainees' academic performance at Eenhana Vocational Training Centre would enable the researcher to suggest teaching and learning strategies to promote the best performance among trainees. It would also contribute to the understanding of trainers about how the trainees' academic performance is affected by the medium of instruction.

\section{RESEARCH METHODOLOGY}

The study aimed to find subjective realities which helped in promoting understanding of real experiences from the chosen research population, the trainees and trainers, about how they perceive the influences of English as a Second Language on their academic performance. It also enabled interaction between the researcher and the 
research participants to give their own experiences and opinions. This method contributed much at getting a lot of ideas from individual trainees and trainers as participants through interviews, observation and report or activities checking. This was the best approach to use as no generalized information was given. Participants were openly expressing themselves, since it was conducted individually, between interviewer and interviewee.

Study partipants were obtained by the snowball sampling technique. '. Participants were trainees in the vocational training centre who had completed their basic education at different schools and were admitted with different entry requirements. Some only completed Grade 10, others went up to Grade 12, while the rest were admitted because of the policy which allows the disadvantaged tribes to be included in education training centres. As the centre has trainees of different academic abilities depending on the levels of basic education achieved, it was quite challenging for the researcher to find different participants according to their categories. Therefore, one participant was selected with the assistance of the trainer and was asked to refer another one to the researcher. This referral chain (snowball) continued until all nine participants were recruited. This sampling method contributed to obtaining the study population at a remarkably low cost (Devkota, 2020). The study population comprised 9 trainees from one class and one trade and 5 trainers. Participants were informed of all relevant rules regarding the study and how their wellbeing was to be protected in a way that they would not be exposed.

\section{DISCUSSION AND INTERPRETATION OF FINDINGS}

It is noted that their proficiency in the language of instruction determines the understanding and performance of trainees in their academic work. In this study, some participants indicated that they get to understand their academic work well, and that is promoted by the advantage of understanding English as the medium of instruction. Adequate understanding of the language of instruction contributes to best academic performance (Aina, Ogundele \& Olanipekun, 2013).

English as a Second Language is noted to play a major role in the trainees' academic performance, as that when they find it difficult to express themselves in English. This also affects the way they perform in other subjects as well, as they may find it challenging to understand and answer academic questions. Some trainees were noted to have used few words when responding to the interview questions posed to them. It shows that they were unable to give detailed information, especially in content subjects which require explanations. This means that for the trainees to perform well academically, then they should be able to demonstrate adequate proficiency in the language of instruction.

It is also noted that trainees perform poorly in their academic work when they cannot understand what is asked, or understand the meaning of questions and the content studied. Trainees require a fairly extensive vocabulary to perform well in their academic work. A poor vocabulary may cause trainees to misinterpret the questions and fail to provide correct information, thus resulting in a poor academic performance (Wilson \& Komba, 2012; Kagwesage, 2012).

\subsection{Challenges Experienced in English as a Second Language by Trainees Across all their Subjects}

Trainees found it difficult to understand some terms used in their subjects due to their low English proficiency levels, and this results in poor academic performance. It is imperative that trainees understand the meaning of words and other expressions used in their academic work for them to perform well. This is because an adequate understanding of the vocabulary aids the learner to interpret questions and provide correct answers. They may find it difficult to contextualize, resulting in undesired academic performance. This was in agreement with Amua-Sekyi, E.T. \& Nti, S. K. (2015) as well as with Wilson \& Komba (2012

\subsection{Understanding or Comprehending of Academic Work}

Some trainees indicated not being able to comprehend their academic work due to limited English proficiency which contributes much to poor academic performance. This can adversely affect academic performance in subjects studied in the English language because it is unlikely that a student will perform optimally in the 
subject if he does not understand the medium of instruction (Kagwesage, 2012). So, trainees need to understand the medium of instruction first for them to comprehend and perform well academically. This places trainees who may not understand the meaning of words or expressions at an academically disadvantaged position whereas those who demonstrate adequate proficiency in the language of instruction may be the best advantage to perform well in their academic work as alluded by Racca \& Lasaten (2016).

\subsection{Relationship between English as a Second Language and other Subjects}

Being good at English as a medium of instruction makes the trainees' academic work easier and perform their best. This only happens when, for instance, they learn certain words in one subject, and they find them used in other subjects, then that would be helpful as it can make them understand the other content (Kagwesage, 2012). When they understand what they are learning, they can be able to understand the assessment activities, answer them correctly and as a result perform well academically.

\subsection{Confidence and Competence in English as a Second Language}

It was noted that trainees found it difficult to speak at length, and some were not at ease. They acted as if they were afraid of making errors. This is an indication that trainees were not confident in what they were saying. That could be caused by not having ideas of what to say, or not being able to express themselves due to limited proficiency in English as a Second Language. The trainees also opted just to be listeners and not be actively involved in a way that they could give answers or participate in class discussion. They were neither able to support nor clarify their points. They also overused or repeated some words in their responses. This indicates a state of inadequate proficiency in the language, and this can have a negative impact on the trainees' academic performance (Mlay, 2010).

\subsection{Interview with Trainers as Participants}

Trainers stated that trainees' competence in English was determined by their academic background and exposure to the language (English as a Second Language). It was noted that their exposure to the language at their previous grades or primary education affects the way trainnes express themselves in English. Trainees who got the best exposure to the language, confidently express themselves in English. This means that proficiency level in English determines their ability to participate, which may enhance best academic performance (Racca \& Lasaten, 2016; Amua-Sekyi, et al 2015).

The trainees also experienced many spelling problems which in most cases affected their best academic performance, as they end up failing because of wrongly spelt answers. However, they perform well in Mathematics and technical subjects as compared to other theoretical subjects. The more uncomplicated structure and style of the English language used in technical subjects usch as Mathematics makes it easier to be understood by trainees (Wilson et al. 2012).

\subsection{Factors in English as a Second Language that Influence Trainees' Academic Performance}

The usage of mother tongues affects the trainee's academic performance negatively, as they try to translate some of their vernacular expressions into English, which may not literally translate into the same expression intended in the English Language. This makes the trainees misinterpret information, and results in academic failure (Wilson et al., 2012; Racca et al., 2016).

The use of grammar or tenses also affects the trainees' academic performance in theoretical subjects which often require extensive expressions in the language of instruction, as they find it challenging to present their answers correctly and in an understandable manner. Djihed (2018) posits that poor command or best command in English as a medium of instruction either makes them perform poorly or adequately in their academic work. 


\subsection{Relationship between English as a Medium of Instruction and other Subjects}

Trainees were noted to have lacked the language basics which enables them to express themselves clearly and to understand and interpret the questions correctly. This means that if the trainees experience difficulties in understanding the subject content or assessment activities due to poor English skills. Trainees need to understand what they are learning for them to be able to comprehend their academic work and perform better (Aina et al., 2013).

\subsection{How well Trainees Comprehend their Academic Work}

Trainees' comprehension of academic work depend on their individual effort and understanding of the language of instruction, which can promote a better understanding of the content taught (Aina et al., 2013). This enhances better performance for those who are proficient in the language, as they can provide the required answers and follow the instructions as per assessments

Those trainees who have problems in the language of instructions end up memorizing what is taught, which may not promote comprehension of what they are learning. These trainees do not always perform well. For instance, if the structure or words they have memorized happens to be changed, they may get confused and be unable to provide correct answers, resulting in academic failure (Kagwesage 2012).

\section{OBSERVATION REPORT}

Some trainees reported difficulty in discussing academic material in their mother tongue, especially in technical work (practical). They only used English when talking to the instructor or trainer. This can be a burden to their academic work as they may find it challenging to understand the instructions and procedures that they may be given by the instructors during individual assessments (Komba 2012, Robelle et al 2016, Ekua et al 2015).

\section{DOCUMENT ANALYSIS}

The document analysis was done in HIV and AIDS module as well as in the assessment marks for English for Communication, HIV and AIDS as well as in Welding and metal fabrication. It was discovered that trainees who understood the questions because of adequate proficiency in English, answered the questions correctly. In assessment marks, those who performed well in English for communication also did well in other subjects. This provides evidence that, being good at the language of instruction, enhances best academic performance (Aina et al., 2013).

\section{SUMMARY}

The study was strengthened by the Zone of Proximal Development theory and guided by the qualitative data collected from the participants that provided information on how English as a Second Language influences trainees academic performance at Eenhana Vocational Training Centre. It was found that the trainees proficiency level in English as a Second Language determine how they perform academically.

\section{RECOMMENDATIONS}

It is recommended that participants for future studies be selected based on their Grade 10 or 12 school leaving certificates. Future studies will need to consider the grade obtained in English as a Second Language in order to get valuable information on the influences of medium of instruction plays in on trainees academic 
performance. The academic performance of those who graduated at Eenhana Vocational Training Centre can also a deeper understanding of the English as a Second Language' influence in the trainees' academic performance. The findings of the study are that the academic performance of trainees is highly influenced by their abilities to use the language. It is on the background of these findings that the following recommendations are made;

- VTCs should introduce a bridging course for trainees to attend before starting their main academic courses which will strictly be in English

- English as a medium of instruction for learning should be taken seriously in basic education and institutions of higher learning

- Trainees should read a lot and practise English activities to acquire vocabulary and improve their grammar

- All trainers should strictly consider the appropriate usage of the language

- There should be learning spots at the centres where trainees can go to learn and practise English besides just learning it in the lessons

- Lastly, as there is an integration of trainees with different school leaving certificates, the Ministry of Higher Education should also make provisions for improvements of different levels of English Language proficiency.

\section{REFERENCES}

Aina, J. K. et al. (2013). Students' Proficiency in English Language Relationship with Academic Performance in Science and Technical Education. American Journal of Educational Research, 1(9), 355-358.

Amua-Sekyi, E.T. \& Nti, S. K. (2015). Factors affecting students' performance in English at colleges of education in Ghana. IMPACT: International Journal of Research in Humanities, Arts and Literature (IMPACT: IJRHAL) ISSN(E): 2321-8878; ISSN(P): 2347-4564 Vol. 3, Issue 10, 29-44.

Culligan K. (2013). The relationship between language and thought exploring Vygotsky and socialcultural approaches to second research. New Brunswick. Canada.

Dahms, M. et al. (2007). The Education Theory of Lev Vygotsky: An Analysis. New Foundations Site. http://www.newfoundations.com/GALLERY/Vygotsky.html. Accessed 11-09-20

Devkota, B. R. (2020). Snowball sampling. Mathstopia. https://www.mathstopia.net/sampling/snowball-sampling. Accessed 25-08-20

Djihed A. (2013). Investigating the reading difficulties of Algerian. Est student with regards to their general English knowledge. Arab world English Journal 4 (1).

Fry, H. et al. (2009). A Handbook for Teaching and Learning in Higher Education: Enhancing Academic Practice 3rd edition. Routledge270 Madison Ave, New York, NY 10016

Frydman J. (2011). A critical analysis of Namibian's English only language. $40^{\text {th }}$ Annual Conference on African Linguistics. Somerville, MA: Cascadilla proceedings project. https://www.lingref.com/cpp/acal/40/paper2574.pdfAccessed 03-03-20

Hanse - Himarwa K. (2017). National promotion policy guide for junior and senior secondary school phases. NIED, Okahandja https://www.simplypsychology.org/Zone-of-Proximal-Development.html. Accessed 14-01-20

Kagwesage, A. M. (2012). Higher education studentse reflections on learning in times of academic language shift. International Journal for the Scholarship of Teaching and Learning, 6/2. Retrieved December, 2015, from: http://academics.georgiasouthern.edu/ijsotl/v6n2.html Accessed 02-05-20

Malwa N.N.L. (2018). Difficulties that level one trainees encounter in learning Mathematics. Windhoek Vocational Training Centre. University of Namibia

McLeod, S. (2019) The Zone of Proximal Development and Scaffolding. Simply Psychology https://www.simplypsychology.org/Zone-of-Proximal-Development.html Accessed 02-08-20

Mlay N. (2010). The influences of the language of instruction on students' academic performance in secondary schools in Africa: A comparative study of urban and rural schools in Arusha-Tanzania, University of Oslo.

Nath. B. K. (2010). Theories of language in learning of Mathematics: Major language theorists influencing learning of Mathematics. University of Calicut, India. 
Racca, R \& Lasaten, R. (2016). English Language Proficiency and Academic Performance of Philippine Science High School Students. International Journal of Languages, Literature and Linguistics. 2. 44-49. 10.18178/IJLLL.2016.2.2.65.

Sadeghi, B. et al. (2013). English Language Proficiency as a predictor of academic achievement among medical students in Iran. Theory practice. Lang. stud. 3 (12):2315 -2321.

Tuncer M. and Dogan Y. (2015). Effect of foreign language classroom anxiety on Turkish University students' academic achievement in foreign language learning. Journal of education and training studies, 3 (6), 14 -19.

Ujjwal K.H. (2018). English Language Anxiety and Academic Achievement. University of Gour Banga, Malda, WB -732103 .

Wilson, J., \& Komba, S. C. (2012). The Link between English Language Proficiency and Academic Performance: A Pedagogical Perspective in Tanzanian Secondary Schools. World Journal of English Language, 2(4). doi:10.5430/wjel.v2n4p1 